\title{
Alcohol consumption in patients with colorectal adenomatous polyps
}

\author{
G F Cope, J I Wyatt, I F Pinder, P N Lee, R V Heatley, J Kelleher
}

\begin{abstract}
The risk of developing colorectal adenomatous polyps is probably increased by a variety of dietary and environmental factors. We found an association with current alcohol and cigarette consumption. The risk of polyps was increased three times in drinkers who did not smoke and two times in smokers who did not drink, with those who both drank and smoked having 12 times the risk of total abstainers. Since colonic adenomatous polyps are generally regarded as premalignant lesions, these results lend support to the view that alcohol consumption may be an important factor in the pathogenesis of colorectal neoplasia, thus reinforcing the proposed polyp/carcinoma sequence in colorectal carcinogenesis. The role of smoking, however, is less clear particularly since the lack of association of colorectal carcinoma and smoking has been reported in many other studies.
\end{abstract}

Although a number of epidemiological studies have reported an association between the risk of developing colorectal carcinoma and a high level of alcohol consumption, ${ }^{12}$ particularly of beer, ${ }^{3-6}$ other studies have failed to find such a relation. ${ }^{78}$ Some experimental models of rectal carcinogenesis have shown that a high chronic intake of ethanol significantly increases the number of rectal tumours ${ }^{9}$ and selectively stimulates epithelial cell proliferation in the rectum. ${ }^{10}$ Other studies using similar experimental techniques have found, however, that alcohol consumption had no effect on tumourigenesis and even suppressed tumour growth. ${ }^{112}$ Although the consumption of alcohol and cigarettes is closely associated, ${ }^{13}$ no correlation between colonic carcinoma and cigarette smoking has been seen. ${ }^{5}$ In fact, colon cancer patients are often included as control subjects with diseases not associated with smoking in case control studies of smoking and other diseases. ${ }^{14}$

Adenomatous colorectal polyps, which are regarded as precancerous lesions, ${ }^{15}$ have been found to be associated with various dietary and environmental factors, ${ }^{16} 17$ including cigarette smoking. ${ }^{18}$ The association of alcohol consumption and adenomatous polyps has, however, been studied little despite the fact that there is a well recognised association between smoking and alcohol consumption, and to a lesser extent coffee consumption. ${ }^{13}$

A recent prospective necropsy study showed that although patients with colonic polyps had no significant differences in diet or smoking history, they drank more alcohol compared with subjects without polyps. The difference, however, reached statistical significance only when the number of polyps was related to the amount of alcohol consumed. ${ }^{19}$

To clarify the inter-relation between smoking, alcohol, and the presence of adenomas we have examined the smoking history and alcohol consumption in patients with colonoscopically and histologically confirmed colorectal adenomatous polyps.

\section{Patients and methods}

Unselected patients attending a routine colonoscopy session were interviewed by one of the authors (GFC) before examination, and a questionnaire was completed that detailed the daily consumption of tea, coffee, and tobacco products and the current weekly consumption of alcoholic beverages. We studied 66 patients $(30$ women) with colorectal adenomatous polyps (mean age 63.3 years) and 86 patients (48 women, mean age 61.3 years) who had no evidence of colorectal polyps at colonoscopy. The latter group comprised patients who were under investigation for possible upper gastrointestinal abnormalities or who attended the clinic because of altered bowel habit. These included approximately equal numbers of patients with the irritable bowel syndrome, diverticular disease, and those with an otherwise normal colon. This group acted as the control group.

Categorical variables were analysed using continuity corrected $\chi^{2}$ tests, with stratification for sex and age (using four age bands 39-49, 50-59, 60-69, and 70-81), and in some analyses, manufactured cigarette smoking (never, ex, current) and for alcohol consumption $(0,1-10,>10$ units). Relative risks were calculated by the Mantel-Haenszel procedure. Continuous variables were analysed using the Fry-Lee nonparametric rank test,,$^{20}$ with some stratification for sex, age, etc. In the Tables, smoking refers to manufactured cigarettes regardless of other products. Omission of five control subjects and eight polyps patients who reported having smoked a pipe, cigars, or handrolled tobacco had no material effect on the conclusions, detailed results not being reported.

\section{Results}

Compared with the control group, the polyp group was found to contain significantly more current smokers $(\mathrm{p}<0.05)$ (Table I). The mean number of manufactured cigarettes smoked by the patients with polyps was approximately the same as that of the smokers in the control group (mean consumption $14 \cdot 1$ and $13 \cdot 2$ cigarettes per day respectively). Current alcohol consumption (units/week) was found to be approximately 
TABLE I Comparison of patients with colonic adenomatous polyps and control subjects with no evidence of colonic neoplasia

\begin{tabular}{|c|c|c|c|}
\hline & Polyp group & Control group & $p$ \\
\hline $\begin{array}{l}\text { No } \\
\text { Women (\%) } \\
\text { Mean age (yrs) } \\
\text { Current smokers }{ }^{\star} \\
\text { Coffee consumption (cups/day) } \\
\text { Tea consumption (cups/day) }\end{array}$ & $\begin{array}{l}66 \\
45 \\
63 \cdot 3 \\
47 \% \\
1 \cdot 50 \\
5 \cdot 09\end{array}$ & $\begin{array}{l}86 \\
56 \\
61 \cdot 3 \\
26 \% \\
1 \cdot 95 \\
4 \cdot 45\end{array}$ & 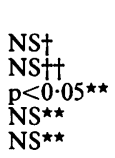 \\
\hline $\begin{array}{l}\text { Alcohol consumption (units/week) } \\
\quad 0 \\
\quad 1-5 \\
6-10 \\
11-20 \\
>20 \\
\text { Mean (units/week) } \\
\text { SE }\end{array}$ & $\begin{array}{l}20(30 \cdot 3 \%) \\
19(28 \cdot 8 \%) \\
10(15 \cdot 2 \%) \\
8(12 \cdot 1 \%) \\
9(13 \cdot 6 \%) \\
8 \cdot 33 \\
1 \cdot 50\end{array}$ & $\begin{array}{l}45(52 \cdot 3 \%) \\
19(22 \cdot 1 \%) \\
8(9 \cdot 3 \%) \\
9(10 \cdot 5 \%) \\
5(5 \cdot 8 \%) \\
4 \cdot 73 \\
0 \cdot 94\end{array}$ & $\mathrm{p}<0 \cdot 01^{\star \star}$ \\
\hline $\begin{array}{l}\text { Joint current smoking and alcohol consumption } \\
\text { Total abstainers (base for comparison) } \\
\text { Smokers only } \\
\text { Drinkers only } \\
\text { Smokers and drinkers }\end{array}$ & $\begin{array}{l}10(15 \cdot 2 \%) \\
10(15 \cdot 2 \%) \\
25(37 \cdot 9 \%) \\
21(31 \cdot 8 \%)\end{array}$ & $\begin{array}{l}34(39 \cdot 5 \%) \\
11(12 \cdot 8 \%) \\
30(34 \cdot 9 \%) \\
11(12 \cdot 8 \%)\end{array}$ & $\begin{array}{l}\text { NS } S^{\star \star} \\
p<0 \cdot 05^{\star \star} \\
p<0 \cdot 01^{\star \star}\end{array}$ \\
\hline
\end{tabular}

doubled in the polyp group compared with the control group $(\mathrm{p}<0.01)$ (Table I). Although $30 \%$ of the patients with polyps reported no current alcohol consumption, this compared with $52 \%$ in the control group. The relative risk of adenomatous polyp according to the degree of alcohol consumption was calculated. For $0,1-5,6-10$, 11-20, and more than 20 units of alcohol per week the relative risks (standardised for age and sex) were $1 \cdot 0,2 \cdot 75,3 \cdot 42,1 \cdot 67$, and $2 \cdot 43$ respectively.

There was no significant difference in the consumption of coffee between the two groups. There was, however, a suggestion of a higher tea consumption in the polyp group, particularly in men, where the difference reached significance compared with control subjects $(p<0.05)$.

Because of the close relation between smoking and alcohol consumption, standardisation was carried out for both smoking and alcohol consumption. Generally, this resulted in a weakening of the associations, although the relation between alcohol and adenomatous polyps remained significant at the $95 \%$ level. Examination of the joint distribution of alcohol and smoking with adenomatous polyps (Table II), shows that smoking alone did not significantly increase the risk of polyps, although alcohol consumption alone resulted in a threefold increase in risk $(p<0.05)$. When smoking and alcohol drinking were combined, however, the risk dramatically increased. The estimated risk was more than 12 times that of non-smokers and non-drinkers $(p<0.01)$ and the relative risk exceeded 10 in both men and women. These

TABLE II Risk of colonic adenomatous polyps in relation to both smoking and alcohol consumption, standardised for age and sex

\begin{tabular}{lllcc}
\hline \multirow{2}{*}{$\begin{array}{l}\text { Current } \\
\text { smoker }\end{array}$} & $\begin{array}{l}\text { Current } \\
\text { drinker }\end{array}$ & \multicolumn{3}{c}{ Relative risk $(95 \%$ confidence limits $)$} \\
\cline { 2 - 5 } & Men & Women & Sexes combined \\
\hline- & - & 1 & 1 & 1 \\
+ & - & 1.52 & $2 \cdot 43$ & $2 \cdot 12(0 \cdot 54-8 \cdot 29)$ \\
- & + & $6 \cdot 48$ & $2 \cdot 03$ & $3 \cdot 04(1 \cdot 14-8 \cdot 15)^{\star}$ \\
+ & + & 19.01 & $10 \cdot 54^{\star}$ & $12 \cdot 70(3 \cdot 02-53 \cdot 42)^{\star \star}$ \\
\hline
\end{tabular}

${ }^{\star} \mathrm{p}<0.05 ;{ }^{\star \star} \mathrm{p}<0.01$
TABLE III Numbers of patients and control subjects stratified by age and sex according to their habit of cigarette smoking, drinking of alcohol, or both

\begin{tabular}{llllll}
\hline Age & Group & $\begin{array}{l}\text { Total } \\
\text { abstainers }\end{array}$ & $\begin{array}{l}\text { Smokers } \\
\text { only }\end{array}$ & $\begin{array}{l}\text { Drinkers } \\
\text { only }\end{array}$ & $\begin{array}{l}\text { Smokers } \\
\text { drinkers }\end{array}$ \\
\hline Men & & & & & \\
$39-49$ & Patient & 0 & 0 & 1 & 2 \\
& Control & 0 & 0 & 6 & 0 \\
$50-59$ & Patient & 0 & 2 & 2 & 1 \\
& Control & 3 & 0 & 4 & 4 \\
$60-69$ & Patient & 1 & 3 & 5 & 7 \\
& Control & 0 & 2 & 5 & 2 \\
$70-81$ & Patient & 2 & 0 & 6 & 4 \\
& Control & 8 & 2 & 2 & 0 \\
Women & & & & & \\
$39-49$ & Patient & 0 & 0 & 3 & 2 \\
& Control & 4 & 2 & 2 & 3 \\
$50-59$ & Patient & 1 & 0 & 3 & 2 \\
& Control & 5 & 2 & 3 & 1 \\
$60-69$ & Patient & 4 & 4 & 5 & 0 \\
& Control & 4 & 1 & 4 & 1 \\
$70-81$ & Patient & 2 & 1 & 0 & 3 \\
& Control & 10 & 2 & 4 & 0 \\
\hline
\end{tabular}

differences are more clearly illustrated in Table III, which shows the number of patients and control subjects according to smoking and drinking habit by sex.

These results indicate that alcohol drinking is strongly associated with the presence of adenomatous polyps in the large bowel, with the risk increasing threefold compared with nondrinkers. Cigarette smoking is also associated with adenomas, but to a lesser extent. It is the combination of these two factors that seems to increase the risk of colorectal adenomatous polyps greatly compared with that in current total abstainers.

\section{Discussion}

Increased alcohol consumption, particularly beer, has been linked with the development of rectal carcinoma in both $\operatorname{man}^{1-5}$ and in experimental models. ${ }^{10}$ Various studies of dietary factors in patients with polyps have shown that adenomatous polyps are associated with a high consumption of fat, sugar, and confectionery and a low consumption of fibre and cruciferous vegetables, in particular. ${ }^{16}{ }^{17}$ Although cigarette smoking has been found to be associated with colonic polyps, ${ }^{18}$ attempts to link colonic carcinoma with smoking have failed. ${ }^{5}$ Despite these extensive surveys there has until now been little attempt to link alcohol consumption and polyp formation.

The present study confirms the association between polyps and cigarette smoking, but shows, in particular, that polyps are also very strongly associated with alcohol consumption, with the risk increasing threefold compared with that in non-drinkers. What may be of most importance, however, is the combined effects of smoking and alcohol consumption, which increased the risk of adenomatous polyps 12 times. This was evident both in men and women.

Interpretation of the results from our study is not completely straightforward. We were unable to collect detailed dietary information and it is possible that some of the association seen with alcohol and tobacco consumption may result from uncontrolled dietary factors. It is also possible that the smoking and alcohol consumption of our control group were not fully repre- 
sentative of the normal healthy population, although it should be pointed out that the relatively low figure of $26 \%$ smokers in the control group is consistent with recent data on consumption of manufactured cigarettes by age collected by the Tobacco Advisory Council.

We also accept that patients attending a colonoscopy clinic are not a true sample of the general population. Since this investigation was designed to differentiate between patients with polyps and those without, however, we preferred to have a control group in whom any chance of polyps or other adenomatous condition has been excluded. Considering that $7 \%$ of asymptomatic subjects with a similar age range have been shown to have colorectal polyps at sigmoidoscopy, ${ }^{21}$ we can be sure that our control group do not have, or have any history of, colorectal polyps.

Nevertheless, we feel that our data indicate that alcohol consumption and, to a lesser extent smoking, increase the risk of adenomatous polyps of the colon, particularly in combination. Although a relation between smoking and colonic polyps has been reported by others, ${ }^{18}$ its relevance is less clear, as it does not seem to agree with the well documented lack of association of smoking with colonic cancer. ${ }^{514}$

Adenomatous polyps are generally regarded as precancerous lesions, although it is understood that only a small proportion of these polyps will ever develop into clinically evident carcinoma. ${ }^{22}$ Taken at face value, our results indicate that the previously recognised association between alcohol and large bowel cancer also encompasses premalignant adenomatous polyps. Thus, the putative role of alcohol in colorectal carcinogenesis seems to be the formation of small adenomas at an early stage. Our study has emphasised a possible association between smoking and alcohol in the epidemiology of these neoplasms, thus indicating that it is the combination of the two factors that greatly increases the risk of developing colorectal adenomas.

This work was sponsored by the Tobacco Advisory Council, while GFC was in receipt of a NACC/BDF research fellowship. IFP is a general practitioner in Castleford, West Yorkshire and a clinical assistant in the Department of Gastroenterology at the Genera Infirmary, Leeds, and PNL is an independent consultant in statistics. We would like to thank Dr L J Kinlen of the CRC Cancer Epidemiology Unit, Edinburgh for his useful criticisms during the preparation of this manuscript.

1 Pollack ES, Nomura AMY, Heilbrun LK, Stemmermann GN, Green SB. Prospective study of alcohol consumption and cancer. New Eng $\mathcal{Y}$ Med 1984; 310: 617-21.

2 Wu AH, Paganini-Hill A, Ross RK, Henderson BE. Alcohol, physical activity and other risk factors for colorectal cancer: A prospective study. $B r \mathcal{F}$ Cancer 1987; 55: 687-94

3 Committee on diet, nutrition and cancer. National Research Council report 1982; National Academic Press. 11.1-11.15.

4 Enstrom JE. Colorectal cancer and beer drinking. Brf Cancer 1977; 35: 674-83.

5 Breslow NE, Enstrom JE. Geographic correlations between cancer mortality rates and alcohol-tobacco consumption in the United States. F Nat Cancer Inst 1974; 53: 631-9.

6 Kune S, Kune GA, Watson LF. Case-control study of alcoholic beverages as etiological factors: The Melbourne alcoholic beverages as etiological factors:

7 Bjelke E. Case-control study of cancer of the stomach, colon, and rectum. In: Clark RL, Cumley RC, McCay JE Copeland MM (eds). Oncology. Chicago: Yearbook Medical Publishers, 1970; 5: 320-34.

8 Higginson J. Etiological factors in gastrointestinal cancer in man. F Natl Cancer Inst 1966; 37: 527-45.

9 Seitz HK, Czygan P, Simanowski U, et al. Stimulation of chemically induced rectal carcinogenesis by chronic ethanol ingestion. Alcol Alcolsm 1985; 20: 427-33.

10 Simanowski UA, Seitz HK, Baier B, Kommerell B, SchmidtGayk H, Wright NA. Chronic ethanol consumption selectively stimulates rectal cell proliferation in the rat. Gut 1986 ; 27: 278-82.

11 Nelson RL, Samelson SL. Neither dietary ethanol nor beer augments experimental colon carcinogenesis in rats. $D$ is augments experimental colon
Colon Rectum 1985; 28: $460-2$.

12 Hamilton SR, Sohn OS, Fiala ES. Effects of timing and quantity of chronic dietary ethanol consumption on azomethane-induced colonic carcinogenesis and azoxymethane metabolism in Fischer 344 rats. Cancer Res 1987 47: 4305-11.

13 Carmody TP, Brischetto CS, Matarazzo JD, O'Donnell RP. Co-occurent use of cigarettes, alcohol, and coffee in healthy, community living men and women. Health Psychol 1985; 4 323-35.

14 Garfinkel L, Auerbach O, Joubert L. Involuntary smoking and lung cancer: A case-control study. $\mathcal{F}$ Natl Ćancer Inst and ling cancer:

15 Morson BC, Dawson IMP. Malignant epithelial tumours. In Gastrointestinal pathology. Oxford: Blackwell Scientific Publications, 1972: 539-73.

16 Hoff G, Moen IE, Trygg K, Frolich W, Sauar J, Vatn M. Epidemiology of polyps in the rectum and sigmoid colon. Evaluation of nutritional factors. Scand $\mathcal{F}$ Gastroenterol 1986; 21: 199-204

17 Macquart-Moulin G, Riboli E, Cornee J, Kaaks R, Berthezene $P$. Colorectal polyps and diet: A case-control study in Marseilles. Int f Cancer 1987; 40: 179-88.

18 Hoff G, Vatn MH, Larsen S. Relationship between tobacco smoking and colorectal polyps. Scand F Gastroenterol 1987; 22: 13-6.

19 Stemmermann GN, Heilbrun LK, Nomura AMY. Association of diet and other factors with adenomatous polyps of the large bowel: a prospective autopsy study. Am $\mathcal{f}$ Clin Nutn large bowel: a p

20 Fry JS, Lee PN. Stratified rank tests. Appl Statistics 1988; 37: 264-6.

21 Ackar E, Carey W. Small polyps found during fiberoptic sigmoidoscopy in asymptomatic patients. Ann Int Med 1988 109: 880-3

22 Stryker SJ, Wolff BG, Culp CE, Libbe SD, Ilstrup DM, MacCarty AL. Natural history of untreated colonic polyps. Gastroenterology 1987; 93: 1009-13. 